\title{
ДИскУССИИ
}

www.volsu.ru

DOI: https://doi.org/10.15688/jvolsu2.2016.4.26

UDC 81'373

Submitted: 07.10.2016

LBC 81.053 .2

Accepted: 10.11.2016

\section{TERMINATION AS THE BASIS FOR CLASSIFICATION OF DOCUMENT TEXTS ${ }^{1}$}

\author{
Marina V. Kosova \\ Volgograd State University, Volgograd, Russian Federation \\ Roza R. Sharipova \\ Volgograd State University, Volgograd, Russian Federation
}

\begin{abstract}
This article discusses the principles of classification of document texts from the point of view of records management and document linguistics; studies features of the terms of fixing the scope of the text (ambiguity, the presence of a strict definition, independent of context) and the scope of the operation (formal and substantial variability and others.); characterizes the specificity of multiple meanings, synonyms and variants of the terms used in the document texts; indicates the factors influencing the selection of the term for the document text.

The authors propose to identify the main types of document texts in terms of terminological vocabulary representation and allocate mixed-type texts along with term-using (scientific, technical documents, secondary documents, etc.), term-fixing (standards, terminological dictionaries, encyclopedias, thesauri, classifications, etc.), and term-generating (documents or scientific texts devoted to document studies).

The article presents the regulation as a document text of mixed type in terms of the use of terminological units. We give a definition of the regulation as the document, which is characterized by its form, the features of compositional structure and content of speech organization of the text; we also analyze the terminology of the field this document, structure recorded therein terminological units. Regulation is defined as a term-using, term-fixing, and a termgenerating text.
\end{abstract}

Key words: document text, regulation, typology of texts, terminology, mixed-type text.

УДК 81 '373

ББК 81.053 .2
Дата поступления статьи: 07.10.2016

Дата принятия статьи: 10.11.2016

\section{ТЕРМИНИРОВАННОСТЬ КАК ОСНОВА КЛАССИФИКАЦИИ ДОКУМЕНТНЫХ ТЕКСТОВ ${ }^{1}$}

\author{
Марина Владимировна Косова \\ Волгоградский государственный университет, г. Волгоград, Российская Федерация \\ Роза Рифатовна Шарипова \\ Волгоградский государственный университет, г. Волгоград, Российская Федерация
}

Аннотация. В статье рассматриваются принципы классификации документных текстов в аспекте доку-
ментоведения и документной лингвистики; отмечаются особенности терминов в текстах сферы фиксации
(однозначность, наличие строгой дефиниции, независимость от контекста) и сферы функционирования (фор-
мальная и содержательная вариативность и др.); характеризуется специфика многозначности, синонимии и
вариантности терминов, использующихся в документных текстах; указываются факторы, влияющие на от-
бор термина для документного текста.
Предлагается уточнить существующую типологию документных текстов с точки зрения представлен-
ности в них терминологической лексики и выделять, наряду с терминоиспользующими (научные, техничес-
кие документы, вторичные информационные документы и др.), терминофиксирующими (стандарты, тер-
минологические словари, справочники, тезаурусы, классификаторы и др.), терминопорождающими (доку- 
менты или научные тексты, посвященные исследованию документа) документными текстами, тексты смешанного типа. В качестве примера такого документного текста рассматривается регламент: дается его дефиниция, характеризуется формуляр, описываются композиционно-содержательная структура и речевая организация текста, анализируются терминология предметного поля этого документа, структура зафиксированных в нем терминологических единиц. Доказано, что регламент совмещает в себе признаки терминоиспользующих, терминофиксирующих и терминопорождающих документных текстов.

Ключевые слова: документный текст, регламент, типология текстов, терминология, текст смешанного типа.

\section{1}

В современной лингвистике документный текст рассматривается как объект особого рода. Исследователи отмечают его экстралингвистическую детерминированность, вызванную процессами стандартизации и унификации, которые определяют специфику отбора и функционирования составляющих текст языковых единиц.

Многообразие ситуаций делового общения не позволяет создать единую классификацию документов. В документоведении используются разные основания для разграничения документов: их происхождение, способ документирования, отношение к аппарату управления, количество затронутых вопросов, ограничение доступа, степень подлинности, сроки хранения, сфера деятельности, способ передачи документов, уровень обобщения и отношения к оригинальной информации [4; 6]. В документной лингвистике учитываются особенности организации текста - его размер, лексико-фразеологический состав, объем словаря, характер использования устойчивых документных средств, степень участия невербальных компонентов, синтаксические параметры, способы представления субъектов [2; 3; 5].

Критерием для классификации документных текстов может также послужить уровень их терминированности.

2

2.1. Классификация текстов с точки зрения использования в них терминологии не является новым научным подходом. Хорошо известно предложенное еще в 70-е гг. XX в. в работах В.П. Даниленко разграничение двух сфер существования терминов - сферы фиксации и сферы функционирования [1]. Под сферой фиксации понимаются терминологи- ческие стандарты, словари, сборники рекомендуемых терминов и т. п. Сферой функциионирования считают научно-техническую литературу (статьи, монографии, коллективные монографии, отчасти произведения научно-популярного характера), документацию, устную речь ученых и т. п.

Выявлены формальные и содержательные различия, которые имеют термины в сфере фиксации и в сфере функционирования.

Так, в сфере фиксации термин, как правило, выступает в некоем идеальном виде, он ограничен одной морфологической формой, освобожден от полисемии, синонимии, омонимии, не зависит от контекста, имеет строгую дефиницию. В сфере функционирования он динамичен, так как реализует заложенное во всех языковых единицах свойство вариативности, не ограничен исходной морфологической формой, несет в себе элементы коннотации контекста, благодаря чему часто не требует строгой вербальной дефиниции. «Именно в процессе функционирования возникают типичные ситуации, нарушающие симметрию языкового знака-термина (появление синонимов, развитие полисемии, омонимии), эволюционирующие, а иногда и революционизирующие научные терминологическо-понятийные системы» [8, с. 33].

Эти «нарушения» имеют место в любом тексте, в том числе и в документном, хотя среди качеств, которые должны характеризовать использующиеся в нем «образцовые термины», отсутствие формальной и семантической вариативности ставятся на одно из первых мест, поскольку именно однозначное соотношение означающего с означаемым ориентировано на передачу точной и недвусмысленной информации, а стандартизованность и унифицированность терминов составляют основу плодотворного профессионального общения. 
Так, в документных текстах реализуется многозначность терминов, что может объясняться спецификой самого терминологического значения, которым является «чистое» (научное) понятие, его способностью развиваться; наличием различных научных школ и направлений; неодинаковой предметной или понятийной отнесенностью терминов; произвольностью термина как языкового знака, его конвенциональностью и другими причинами. При этом наиболее распространенным видом многозначности в документах является метонимический перенос (например, резолючия: 1) надпись на служебном документе, содержащая указание, рекомендации, 2) решение, принимаемое съездом; управление: 1) сознательное целенаправленное воздействие со стороны субъектов на экономические объекты, 2) крупное подразделение высших органов управления; платеж: 1) уплачиваемая сумма, 2) процедура возмещения деньгами чего-либо).

Представлена в текстах документов и синонимия, которая в терминологии имеет свою специфику. «Чистая» понятийность терминологического значения обусловливает появление терминов-дублетов. Случаи существования дублетных наименований в пределах одного языка встречаются редко (входящий документ - поступивший документ; исходящий документ - отправляемый документ); как правило, синонимы - это параллельные наименования из разных языков (менеджмент управление; договор - контракт; андеррайтер - поручитель; овертайм - сверхурочное время). Широкое использование в современных документах иноязычной терминологии оправдано экстралингвистическими и собственно лингвистическими факторами и несколько меняет сложившееся отношение к нормам терминоупотребления. Требование своеязычности терминов, в соответствии с которым по возможности необходимо избегать необоснованных иноязычных заимствований и отдавать предпочтение употреблению исконных единиц, в определенной степени противоречит тенденции к межнациональному согласованию терминологии, являющемуся естественным следствием «интернационализации» документов, ориентации на межкультурное общение, подведение их под образцы, что отвечает за- дачам практической деятельности, развитию международных деловых контактов.

Явление вариантности в терминологии обнаруживается прежде всего в сфере многокомпонентных терминологических словосочетаний (налог на землю - земельный налог; документы - документация - система документаичи; УСД - унифииированная система документации; СД - система документации; ДОУ - документационное обеспечение управления; управленческий прочесс - прочесс управления; система документации - документационная система; документ личного происхождения личный документ; карточка фонда - фондовая карточка). Если синонимы представляют собой разные единицы (лексемы или словосочетания), то варианты - это разновидности одной единицы, различающиеся формой и выражающие одно и то же понятие, их употребление обосновано неодинаковыми условиями контекста.

На отбор термина для документа оказывают влияние многие факторы: существенность отраженного в названии признака, общепринятость, языковые качества названия (словообразовательная продуктивность, грамматические особенности, краткость, благозвучие и др.). Невозможность совмещения всех качеств в одном слове вызывает и поддерживает синонимию и вариантность терминологических единиц.

Разграничение сферы фиксации и сферы функционирования стало первым, очень широким основанием для типологии текстов. Далее этот вопрос получил свое развитие, что привело к появлению более конкретных классификаций.

2.2. На наш взгляд, теоретическое значение и практическую ценность имеет общая классификация текстов, предложенная В.М. Лейчиком, в основе которой лежит признак терминированности текста и в соответствии с которой можно говорить о трех типах текстов: терминоиспользующих, терминофиксирующих и терминопорождающих [7, c. 82-83].

С опорой на эту классификацию среди документных текстов с учетом особенностей употребления в них терминов можно выделить прежде всего тексты двух типов: 
1) терминоиспользующие, в которые термины входят будучи уже закрепленными в лексической системе языка, известными получателю текста (разного рода научные, технические документы, вторичные информационные документы, статьи обзорного характера и т. п.);

2) терминофиксирующие, в которых используются термины, уже существовавшие к моменту создания данных текстов, но фиксируемые ими как обязательные, рекомендуемые или, напротив, как нерекомендуемые, недопустимые (стандарты, толковые терминологические словари, справочники, тезаурусы, многие виды классификаторов, некоторые учебники и т. п.) [7, с. 82-83].

Оппозиция документных текстов применительно к сфере деловой коммуникации довольно долго оставалась бинарной (терминоиспользующие / терминофиксирующие), так как документоведение зарождалось и много лет существовало как технология, ремесло. Однако обобщение и осмысление практического опыта привело к становлению документоведения как науки, ее развитию, обусловленному рядом социальных и общенаучных потребностей, к ее очевидному содержательному изменению, что нашло отражение в смене названий данной предметной области: «Докуменоведение» $\rightarrow$ «Документационое обеспечение управления» $\rightarrow$ «УПравление документацией». Появление новой научной специальности 05.25.02 «Документалистика, документоведение, архивоведение», большого количества научных работ разных жанров - статей, монографий, учебников и др., а также расширение видов документных текстов и сфер деловой коммуникации сделало бинарную оппозицию трехчленной: появились тексты третьего типа- терминопорождающие, в которых авторы впервые вводят новые термины в процессе формулирования и изложения новой теории, концепции, нового изобретения или открытия (сфера теории, где термины еще только появляются и «кристаллизуются») [7, с. 83].

Документные тексты разных типов взаимодействуют между собой.

Термины рождаются в сфере функционирования, там меняются их значение и форма, то есть детерминирующими в отношении «терминофиксирующие тексты - терминоиспользующие - терминопорождающие тексты» являются последние, что время от времени требует корректировки текстов первого типа, в частности стандартов, приведения их в соответствие с состоянием науки и, следовательно, упорядочения обозначающих научные понятия терминологических единиц.

Вопросы терминологии, ее нормирования, стандартизации и унификации являются чрезвычайно важными для сферы деловой коммуникации. Точность и однозначность используемых в документном тексте терминов не только влияет на эффективность деловой деятельности, но и обеспечивает правовую защиту субъектов. Документный текст содержит терминологию как отражаемой им предметной области, так и собственную, «документоведческую», обозначающую понятия сферы делопроизводства и управления документацией, которая как результат процессов систематизации и унификации терминов находит отражение в терминофиксирующих текстах - словарях, справочниках, классификаторах, стандартах, где представлен перечень терминов, определено их значение, закреплены сфера и нормы употребления. Рекомендациями стандартов руководствуются в своей работе документоведы-практики, применяя термины в текстах официально-деловых документов, то есть в терминоиспользующих текстах.

Изучение движения терминологии от терминопорождающих к терминоиспользующим и терминофиксирующим текстам, корректировка терминологического аппарата последних стали важным вектором лингвистического анализа, так как исследование реально бытующих в тексте терминов позволяет выявить закономерности их создания и специфику употребления в социальной практике.

2.3. Отмеченные три типа текстов характеризуют отдельные документы разных видов, которые хотя и взаимодействуют между собой, но являются самостоятельными объектами. Однако в настоящее время стремление к эффективной деловой коммуникации, к точности текста, к удобству организации информации обусловливает появление документных текстов «смешанного характера», сочетающих в себе фрагменты терминофиксирующего, терминоиспользующего и терми- 
нопорождающего типов текста. Примером такого документа является регламент.

Регламент - это «устав, свод правил, устанавливающий порядок работы, деятельности» (МАС, с. 694), соответственно, с точки зрения управленческой практики регламент - это документ, в котором перечислены те или иные функции, повторяющиеся действия, сроки их исполнения в целях упорядочения определенного участка деятельности. Помимо того, что регламент является средством организации работы, он дает возможность детально проанализировать реально существующий бизнес-процесс, оценить дублирование действий, устранить лишние этапы, которые нередко имеют место в производственной практике.

В сфере управления регламент используется для документирования самых разных бизнес-процессов. Одним из важных в настоящее время видов деятельности является заключение и реализация договоров. Поэтому применение регламента в качестве инструмента регулирования договорных отношений с партнерами, безусловно, позволяет упорядочить этот процесс, распределить зоны ответственности в рамках ведения договорной работы, документировать процессы учета, контроля места нахождения и организации хранения договоров, сделать их понятными и прозрачными для участников отношений на каждом этапе, устранить разногласия и непонимание, исключить возможные конфликтные ситуации, сохранить и укрепить долгосрочные деловые связи [9].

Назначение регламента как документа определяет особенности его формуляра и речевой организации.

Так, формуляр регламента о процедуре заключения договоров с точки зрения композиционно-содержательной структуры имеет несколько разделов: 1) Общие положения; 2) Термины и сокращения, используемые в Регламенте; 3) Формы и виды договоров; 4) Подготовка к заключению договора; 5) Порядок регистрации договоров; 6) Порядок заключения договоров; 7) Ответственность за неисполнение Регламента; 8) Приложения.

Из наименований разделов видно, что текст документа не является однородным, его можно считать текстом смешанного типа, так как раздел 2 «Термины и сокращения, используемые в Регламенте» представляет собой терминологический словарь, то есть терминофиксирующий текст, в то время как остальные разделы являются терминоиспользующими и терминопорождающими текстами.

Словарь предваряет собственно описание процесса и нужен для того, чтобы избежать нежелательных явлений, которые возможны при функционировании терминов в тексте многозначности, синонимии, вариантности, нарушающих однозначное соответствие формы и содержания языковой единицы и создающих коммуникативные преграды. В словаре представлена основная терминология, ключевые для данного документа термины и их дефиниции. Например, в документе, регламентирующем договорную работу, содержатся термины обозначенной в теме предметной сферы:

Виза - письменное согласие или замечание (дополнения) лица, участвующего в подписании договора, на визовом листе.

Доверенность - документ, удостоверяющий полномочия предъявителя как представителя организации.

Договор (контракт) - соглашение с Контрагентом, которым устанавливаются, изменяются или прекращаются права и обязанности сторон.

Договорная работа - деятельность по подготовке, согласованию, подписанию, регистрации и контролю за исполнением договоров, заключаемых с зарубежными партнерами.

Контрагент - юридическое лицо, с которым организация вступает в договорные отношения.

Куратор договора - сотрудник (ответственный менеджер, руководитель отдела), заинтересованный в заключении договора, ответственный за согласование, заключение и исполнение Договора.

$\mathbf{K \Phi ~ - ~ к о н т р о л ь н а я ~ ф о р м а . ~}$

Приложение к договору - визовый лист, карта партнера, акт, спецификация и т. п.

Протокол разногласий - документ, равнозначный проекту договора, изменяющий условия договора в пользу составившей его стороны.

Протокол согласования разногласий - документ, устраняющий противоречия разногласий.

Руководитель Куратора - начальник отдела, сотрудником которого является ответственный за заключение договора, участвующий в согласовании договора.

Спецификация - прилагаемый к тексту договора документ, в который включаются данные, характеризующие предмет поставки (то есть отража- 
ющие существенные условия договора); в ряде случаев это цена, сроки поставки и иные условия.

Учредительные документы (УД) - документы Контрагента, необходимые для заключения договора.

(Регламент о порядке заключения и оформления договоров, утвержденный приказом директора ООО «Альфа Компьютер» от 27.07.2012 № 05-B. URL: www.alfacomputer.ru).

Терминологический словарь включает только базовые термины, то есть те, которые выражают основные понятия отражаемой документом предметной области: наименования участников (субъектов) деловой коммуникации, документов, делового процесса.

По структуре термины являются однословными (договор / контракт, контрагент, виза, доверенность), двусловными (руководитель куратора, куратор договора, учредительные документы) или трехсловными (протокол согласования разногласий) терминологическими словосочетаниями. Эти термины активно используются в тексте документа:

Оформленный договор регистрируется ответственным за договорную работу в реестре по видам договоров, заключаемых Обществом. Необходимые данные по проекту договора на стадии подготовки куратором договора обязательно заносятся в базу договоров в КФ. На каждый договор в КФ заполняется карточка со всеми реквизитами Контрагента. Контроль за своевременным и правильным оформлением документов в КФ осуществляет руководитель Куратора договора. Перед подписанием договора Куратор обязан скорректировать данные, внесенные в КФ в соответствии с внесенными изменениями при согласовании.

Процессы, деятельность, которые регулируются регламентом, специфичны, именно в целях упорядочения этой деятельности создается регламент, и, как следствие, возникает необходимость «называния» новых явлений и процессов, участников. Таким образом, некоторые термины, которые зафиксированы в словаре регламента, имеют особое значение только в рамках регулируемой им деятельности. Соответственно, документ выступает как терминопорождаюший текст. Так, при разработке Регламента об организации работы с аукционами были созданы следующие термины, которые включены в его словарь:
АМ (аукционный менеджер) - сотрудник, назначенный ответственным за контроль актуальности информации (реквизитов), состояния лицевого счета Компании, размещение информации, документов и движение размещаемых документов на торговых площадках.

OK в HBS - отметка «OК» в HBS, свидетельствующая о получении документов, возможности отгрузки и проведения сделки.

МП (менеджер по поиску) - сотрудник Callцентра, назначенный ответственным за поиск, отбор и информирование РО и АМ о проводимых аукционах

(Регламент об организации работы с аукционами, утвержденный приказом директора ООО «Альфа Компьютер» от 17.08.2012 № 07-В. URL: www.alfacomputer.ru).

3

Применение лингвистических критериев к оценке документных текстов дополняет сложившиеся представления о типологии документов, позволяет выявить особенности документов разных видов, скорректировать нормы терминоупотребления, выработать принципы унификации терминологических единиц.

Документные тексты смешанного типа, в силу компактного, тематически организованного представления информации, экспликации понятийного аппарата предметной сферы, получают все больше распространение в делопроизводственной практике, поэтому научное исследование таких текстов является перспективной задачей современной документной лингвистики.

Терминированность может быть основанием классификации не только современных, но и исторических документов, поскольку позволит охарактеризовать процессы становления и изменения их речевой структуры.

\section{ПРИМЕЧАНИЕ}

${ }^{1}$ Работа выполнена при финансовой поддержке Российского гуманитарного научного фонда и Администрации Волгоградской области, проект № 16-14-34004 «Динамика текстовой и языковой организации региональных документов XVIIIXIX вв. (по данным архивного фонда “Михайловский станичный атаман” ГАВО)». 


\section{СПИСОК ЛИТЕРАТУРЫ}

1. Даниленко, В. П. Лексико-семантические и грамматические особенности слов-терминов / В. П. Даниленко // Исследования по русской терминологии. - М. : Наука, 1971. - С. 7-68.

2. Косова, М. В. Метод документоведческого анализа в лингвистических исследованиях: содержание и цели / М. В. Косова // Вестник Волгоградского государственного университета. Серия 2, Языкознание. - 2016. - Т. 15, № 1. - C. 7-17. - DOI: http://dx.doi.org/10.15688/jvolsu2.2016.1.1.

3. Косова, М. В. Русская Правда: признаки формирующегося законодательного документа / М. В. Косова // Тысячелетие Русской Правды обретение новых смыслов : тез. науч. конф. (Волгоград, 21-22 апреля 2016 г.) - Волгоград : Изд-во ВолГУ, 2016. - С. 80-84.

4. Кузнецова, Т. В. Делопроизводство (документационное обеспечение управления) / Т. В. Кузнецова. - М. : Бизнес-Школа Интел-Синтез, 2002. $374 \mathrm{c}$.

5. Кушнерук, С. П. Документная лингвистика / С. П. Кушнерук. - Волгоград : Волгогр. науч. изд-во, 2007. $-245 \mathrm{c}$.

6. Ларьков, Н. С. Документоведение/ Н. С. Ларьков. - М. : Восток-Запад, 2006. -427 c.

7. Лейчик, В. М. Особенности функционирования терминов в тексте / В. М. Лейчик // Филологические науки. - 1990. - № 3. - С. 80-87.

8. Лемов, А. В. Система, структура и функционирование научного термина / А. В. Лемов. Саранск : Изд-во Мордовского ун-та, 2000. - 192 с.

9. Шарипова, Р. Р. Эффективная договорная работа. Разрабатываем регламент о порядке заключения и оформления договоров / Р. Р. Шарипова // Современные технологии делопроизводства и документооборота. - 2012. - № 12. - С. 54-61.

\section{СЛОВАРИ}

$M A C$ - Словарь русского языка : 4 т. / под ред. А. П. Евгеньевой. - 4-е изд., стер. - М. : Рус. яз. ; Полиграфресурсы, 1999. - Т. III. -725 с.

\section{REFERENCES}

1. Danilenko V.P. Leksiko-semanticheskie i grammaticheskie osobennosti slov-terminov [LexicoSemantic and Grammatical Particular Qualities of WordTerms]. Issledovaniya po russkoy terminologii
[Research on the Russian Terminology]. Moscow, Nauka Publ., 1971, pp. 7-68.

2. Kosova M.V. Metod dokumentovedcheskogo analiza v lingvisticheskikh issledovaniyakh: soderzhanie i tseli [Documental Analysis in Linguistic Research: Content and Objectives]. Vestnik Volgogradskogo gosudarstvennogo universiteta. Seriya 2, Yazykoznanie [Science Journal of Volgograd State University. Linguistics], 2016, no. 1 (30), pp. 717. DOI: http://dx.doi.org/10.15688/jvolsu2.2016.1.1.

3. Kosova M.V. Russkaya Pravda: priznaki formiruyushchegosya zakonodatelnogo dokumenta [Russkaya Pravda: the Emerging Signs of a Legislative Instrument]. Tysyacheletie Russkoy Pravdyobretenie novykh smyslov: tez. nauch. konf. (Volgograd, 21-22 aprelya 2016 g.) [Millennium of Pravda - Finding New Meanings: Abstracts of Scientific Conference (Volgograd, April 21-22, 2016)]. Volgograd, Izd-vo VolGU, 2016, pp. 80-84.

4. Kuznetsova T.V. Deloproizvodstvo (dokumentatsionnoe obespechenie upravleniya) [Office-Work (Documentary Coverage of Management)]. Moscow, Biznes-Shkola Intel-Sintez Publ., 2002. 374 p.

5. Kushneruk S.P. Dokumentnaya lingvistika [Documentary Linguistics]. Volgograd, Volgogradskoe nauchnoe izdatelstvo, 2007. $245 \mathrm{p}$.

6. Larkov N.S. Dokumentovedenie [Documentation Studies]. Moscow, Vostok-Zapad Publ., 2006. 427 p.

7. Leychik V.M. Osobennosti funktsionirovaniya terminov v tekste [Features of Terms Functioning in the Text]. Filologicheskie nauki, 1990, no. 3, pp. 80-87.

8. Lemov A.V. Sistema, struktura $i$ funktsionirovanie nauchnogo termina [The System, Structure and Functioning of the Scientific Term]. Saransk, Izd-vo Mordovskogo un-ta, 2000. 192 p.

9. Sharipova R.R. Effektivnaya dogovornaya rabota. Razrabatyvaem reglament o poryadke zaklyucheniya i oformleniya dogovorov [Effective Contract Work. We Develop Regulations on the Procedure for Conclusion and Registration of Contracts]. Sovremennye tekhnologii deloproizvodstva i dokumentooborota, 2012, no. 12, pp. 54-61.

\section{DICTIONARIES}

Evgenyeva A.P., ed. Slovar russkogo yazyka. V 4 t. T. 3 [Dictionary of the Russian Language. In 4 vols. Vol. 3]. Moscow, Rus. yaz. Publ.; Poligrafresursy Publ., 1999. 725 p. 


\section{Information About the Authors}

Marina V. Kosova, Doctor of Sciences (Philology), Professor, Department of Russian Language and Documentation Studies, Volgograd State University, Prosp. Universitetsky, 100, 400062 Volgograd, Russian Federation, kosowa@mail.ru, iryas@volsu.ru.

Roza R. Sharipova, Postgraduate Student, Department of Russian Language and Documentation Studies, Volgograd State University, Prosp. Universitetsky, 100, 400062 Volgograd, Russian Federation, sharipova_rose@mail333.com, iryas@volsu.ru.

\section{Информация об авторах}

Марина Владимировна Косова, доктор филологических наук, профессор кафедры русского языка и документалистики, Волгоградский государственный университет, просп. Университетский, 100, 400062 г. Волгоград, Российская Федерация, kosowa@mail.ru, iryas@volsu.ru.

Роза Рифатовна Шарипова, аспирант кафедры русского языка и документалистики, Волгоградский государственный университет, просп. Университетский, 100, 400062 г. Волгоград, Российская Федерация, sharipova_rose@mail333.com, iryas@volsu.ru. 